Pacific Journal of Mathematic 


\title{
ON THE COMPLETENESS OF SEQUENCES OF PERTURBED POLYNOMIAL VALUES
}

\author{
STEFAN A. BurR
}

If $S$ is an arbitrary sequence of positive integers, define $P(S)$ to be the set of all integers which are representable as a sum of distinct terms of $S$. Call a sequence $S$ complete if $P(S)$ contains all sufficiently large integers, and $s u b$ complete if $P(S)$ contains an infinite arithmetic progression. We will prove the following theorem: Let $n$th term of the integer sequence $S$ have the form $f(n)+O\left(n^{\alpha}\right)$, where $f$ is a polynomial and where $0 \leqq \alpha<1$; then $S$ is subcomplete. We further show that $S$ is complete if, in addition, for every prime $p$ there are infinitely many terms of $S$ not divisible by $p$. (We call any sequence satisfying this last property an $R$-sequence.) We will then extend these results to considerably more general sequences.

It can be shown in various ways ([3], [4]) that if $f$ is a polynomial which maps positive integers to positive integers, then the sequence $S=\{f(1), f(2), \cdots\}$ is subcomplete, and if in addition $S$ is an $R$-sequence, $S$ is complete. In this work we use results of Folkmann's fine paper [2] to generalize these results to perturbed polynomial sequences $f(1)+t(1), f(2)+t(2), \cdots$, where $t$ is a function with sufficiently slow growth. We first state two results of [2].

THEOREM A (Folkman). Let $A=\left\{a_{n}\right\}$ be a nondecreasing sequence of positive integers satisfying $a_{n}=O\left(n^{\alpha}\right)$ for some $0 \leqq \alpha<1$. Then $A$ is subcomplete.

THEOREM B (Folkman). Let $A=\left\{a_{n}\right\}$ be a nondecreasing sequence of positive integers with disjoint subsequences $\left\{b_{n}\right\},\left\{c_{n}\right\}$, and $\left\{d_{n}\right\}$. Suppose that

$$
\lim _{n \rightarrow \infty} \frac{1}{b_{n+m}} \sum_{i=1}^{n} b_{i}=\infty \cdot \text { for each } m>0,
$$

that $c_{n}>d_{n}$ for each $n$, and that the sequence $\left\{c_{n}-d_{n}\right\}$ is subcomplete. Then $A$ is subcomplete.

We now state

THEOREM 1. Let $S=\left\{s_{1}, s_{2}, \cdots\right\}$ be asequence of positive integers of the form $s_{n}=f(n)+O\left(n^{\alpha}\right)$ where $f$ is a polynomial of degree $\geqq 1$ and $0 \leqq \alpha<1$. Then $S$ is subcomplete. 
Before proving this theorem we first state the case $k=1$ of it as a lemma. The author is grateful to Carl Pomerance of the University of Georgia for the lemma in its present form. The autho's verion of this lemma required $\alpha<1 / 2$, and Theorems 1,3 , and 4 were correspondingly weaker.

LEMma 1 (Pomerance). Let $S=\left\{s_{1}, s_{2}, \cdots\right\}$ be a sequence of integers of the form $s_{n}=a n+O\left(n^{\alpha}\right)$, where $a>0$ and $0 \leqq \alpha<1$. Then $S$ is subcomplete.

Proof. Let $t_{n}$ be the sequence $S$ arranged in nondecreasing order. If $t_{n}=s_{m}$, it is clear that $|m-n|=O\left(n^{\alpha}\right)$, so that

$$
t_{n}=a m+O\left(m^{\alpha}\right)=a n+O\left(n^{\alpha}\right) .
$$

Hence we may assume without loss of generality that $S$ is monotone nondecreasing. Write $s(n)$ for $s_{n}$ and form three disjoint subsequences of $S$ given by

$$
\begin{aligned}
& b_{n}=s(3 n+2), \\
& c_{n}=s\left(3\left[n+M n^{\alpha}\right]+1\right), \\
& d_{n}=s(3 n),
\end{aligned}
$$

where $M$ is large enough that $c_{n}>d_{n}$ for all $n$. Then $0<c_{n}-d_{n}=$ $O\left(n^{\alpha}\right)$ for all $n$. Let $\left\{e_{n}\right\}$ be the sequence $\left\{c_{n}-d_{n}\right\}$ in nondecreasing order. Then

$$
e_{n} \leqq \max _{1 \leqq i \leqq n}\left(c_{i}-d_{i}\right)=O\left(n^{\alpha}\right),
$$

and by Theorem $\mathrm{A},\left\{e_{n}\right\}$, and hence $\left\{c_{n}-d_{n}\right\}$, is subcomplete. Hence, by Theorem B, $S$ is subcomplete. This completes the proof.

Proof of Theorem 1. The case $k=1$ is just Lemma 1, so we assume the theorem to have been proved for some degree $k \geqq 1$. Let $S$ satisfy the hypotheses with $f$ having degree $k+1$. Without loss of generality we may assume that $S$ is strictly increasing. Form three disjoint subsequences of $S$ given by $b_{n}=s_{3 n}, c_{n}=s_{3 n-1}$, $d_{n}=s_{3 n-2}$. Then

$$
\lim _{n \rightarrow \infty} \frac{1}{b_{n+m}} \sum_{i=1}^{n} b_{i}=\infty
$$

for any $m$, and $c_{n}-d_{n}=f_{0}(n)+O\left(n^{\alpha}\right)$, where $f_{0}$ is a polynomial of degree $k$. Thus $\left\{c_{n}-d_{n}\right\}$ is subcomplete by the induction hypothesis, and hence $S$ subcomplete by Theorem B. This completes the proof.

Note that Theorem 1 does not require $f$ to be integer-valued, or even to have rational coefficients. We will see later that Theorem 
1 can be made considerably more general than this. We also remark that Theorem 1 can be proved for bounded perturbations by means of Theorem $\mathrm{B}$ alone. To get the full result we must use the powerful Theorem $\mathrm{A}$.

We will prove a theorem which enables us to conclude that an $R$-sequence satisfying the hypotheses of Theorem 1 is complete. Some preliminary results are necessary. We first state two further theorems taken from [2] and [3] respectively.

TheOREM C (Folkman). Let $B=\left\{b_{1}, b_{2}, \cdots\right\}$ be an increasing sequence satisfying (1). Then for each integer $r>0$, there is an integer $q(r)$ such that for any $k \geqq 0$, at least one of the numbers

$$
(k+1) r, \quad(k+2) r, \cdots,(k+q(r)) r
$$

is in $P(B)$.

Theorem D (Graham). Let $A$ be an $R$-sequence. Then for any integer $m, P(A)$ contains a complete system of residues modulo $m$.

We next prove three simple lemmas.

LEMMA 2. Let $S$ be a sequence with disjoint subsequences $A$ and $B$. If $A$ is an $R$-sequence and $B$ is subcomplete, then $S$ is complete.

Proof. Since $B$ is subcomplete, $P(B)$ contains an infinite arithmetic progression $\{r+u, 2 r+u, \cdots\}$. By Theorem $\mathrm{D}, P(A)$ contains a complete system of residues modulo $r$, say $k_{1}<k_{2}<$ $\cdots<k_{r}$. Let $n$ be any number $\geqq r+u+k_{r}$. For some $k_{i}$ we have $k_{i} \equiv n-u(\bmod r)$. Then $\left(n-u-k_{i}\right) / r$ is an integer $j \geqq 1$. Thus $n=(j r+u)+k_{i}$. Since $k_{i} \in P(A)$ and $j r+u \in P(B), n \in P(S)$. Thus $S$ is complete.

LEMMA 3. Let the increasing sequence $B=\left\{b_{n}\right\}$ satisfy (1). Let $B^{\prime}=\left\{b_{n}^{\prime}\right\}=\left\{b_{i_{n}}\right\}$ be a subsequence of $B$ with $i_{n+1} \leqq i_{n}+2$. Then $B^{\prime}$ satisfies (1).

Proof. Let $b_{n}^{\prime}=b_{j}$. Then

$$
\begin{aligned}
\frac{1}{b_{n+m}^{\prime}} \sum_{i=1}^{n} b_{i}^{\prime} & \geqq \frac{1}{b_{j+2 m}}\left(b_{j}+b_{j-2}+\cdots\right) \\
& \geqq 1 / 2 \frac{1}{b_{j+2 m}} \sum_{i=1}^{j} b_{i} .
\end{aligned}
$$

But the last expression $\rightarrow \infty$ as $j \rightarrow \infty$ for any $m$; so $B^{\prime}$ satisfies (1). 
LEMma 4. Let $A$ be a subcomplete sequence, and let $B$ be an increasing sequence satisfying (1). Then it is possible to form a subcomplete sequence $B^{\prime}$ by adjoining to $B$ a finite number of terms of $A$.

Proof. Let $P(A)$ contain the infinite arithmetic progression $\{r+u, 2 r+u, \cdots\}$. By Theorem $\mathrm{C}$ there is a $q$ such that for any $k \geqq 0$, at least one of $(k+1) r, \cdots,(k+q) r$ is in $P(B)$. It is clear that there is a finite subsequence $A_{0}$ of $A$ such that $P\left(A_{0}\right)$ contains all the numbers $r+u, 2 r+u, \cdots, q r+u$. Let $j \geqq q+1$, and choose $i$ among $j-q, \cdots, j-1$ so that $i r$ is in $P(B)$. Then $j r+$ $u=i r+(j-i) r+u$. But $(j-i) r+u \in P\left(A_{0}\right)$. Thus any number $j r+u$ with $j \geqq q+1$ is a sum of a number in $P\left(A_{0}\right)$ and a number in $P(B)$. Therefore if we form $B^{\prime}$ by adjoining the terms of $A_{0}$ to $B$, we see that $B^{\prime}$ is subcomplete.

We are now in a position to prove

THEOREM 2. Let $S$ be an $R$-sequence which is increasing, with disjoint subsequences $A=\left\{a_{n}\right\}$ and $B=\left\{b_{n}\right\}$. If $A$ is subcomplete and $B$ satisfies (1), then $S$ is complete.

Proof. Let $Q=\left\{q_{1}, q_{2}, \cdots\right\}$ be the set of all primes $q$ with the property that there are infinitely many terms of $B$ which are not divisible by $q$. We must partition $B$ into two subsequences $B_{0}$ and $B_{1}$, where for each $q \in Q, B_{0}$ has infinitely many terms not divisible by $q$, and where $B_{1}$ satisfies (1). This can be done in the following manner. First put into $B_{0}$ a term $b_{i}$ not divisible by $q_{1}$. Next put into $B_{0}$ a term $b_{i+j}, j \geqq 2$, not divisible by $q_{2}$. Continue to place terms $b_{i}$ into $B_{0}$, where successively the terms are not divisible by $q_{1}, q_{2}, q_{1}, q_{2}, q_{3}, q_{1}, q_{2}, q_{3}, q_{4}, \cdots$; this can be done so that each term chosen has an index at least two greater than the previous one chosen. This defines $B_{0}$. But by construction $B_{1}$, formed by the terms remaining, satisfies the hypothesis of Lemma 3 . Thus we have accomplished the desired partition.

We now apply Lemma 4 to the sequences $A$ and $B_{1}$ to form a subcomplete sequence $B_{2}$ consisting of the terms $B_{1}$ and a finite number of terms of $A$. Now form a sequence $A_{1}$ consisting of all terms of $S$ not in $B_{2}$. Then $A_{1}$ is an $R$-sequence, since $S$ is an $R$ sequence and since any prime $q$ which is a non-divisor of infinitely many terms of $B_{2}$ also is a nondivisor of infinitely many terms of $B_{0}$, and hence of $A_{1}$. Thus $S$ has the disjoint subsequences $A_{1}$ and $B_{2}$, with $A_{1}$ an $R$-sequence and $B_{2}$ subcomplete. Therefore, by Lemma $4, S$ is complete. 
We may now derive our desired result on perturbed polynomials as an easy corollary to Theorem 2 .

THEOREM 3. Let S satisfy the conditions of Theorem 1, and let $S$ be an $R$-sequence. Then $S$ is complete.

Proof. Let $S_{1}=\left\{s_{1}, s_{3}, \cdots\right\}$ and $S_{2}=\left\{s_{2}, s_{4}, \cdots\right\}$. Then $s_{1}$ is subcomplete since it satisfies the conditions of Theorem 1 , and $S_{2}$ clearly satisfies (1), and may be assumed without loss of generality to be increasing. Hence $S$ is complete by Theorem 2, and the result is proved.

It is possible to extend Theorems 1 and 3 to considerably more general sequences, namely ones in which $f$ is a "polynomial" with nonintegral exponents. Specifically, we have

THEOREM 4. Let $a_{1}, a_{2}, \cdots, a_{r}$ and $\gamma_{1}>\gamma_{2}>\cdots>\gamma_{r}$ be real numbers, where $a_{1}>0$ and $\gamma_{1} \geqq 1$. Let $f(n)=a_{1} n^{r_{1}}+a_{2} n^{\gamma_{2}}+\cdots+$ $a_{r} n^{r}$. Let $S=\left\{s_{1}, s_{2}, \cdots\right\}$ be a sequence of positive integers of the form $s_{n}=f(n)+O\left(n^{\alpha}\right)$. Then $S$ is subcomplete. If in addition, $S$ is an $R$-sequence, $S$ is complete.

Proof. The proof is very similar to that of Theorems 1 and 3 , so we will not carry out all the details. The proof for $1 \leqq \gamma_{1}<2$ is the same as for Lemma 1 , except that $a n$ is replaced by $f(n)$ and $\alpha$ is replaced by

$$
\max \left(\alpha, \gamma_{1}-1, \max _{\gamma_{i}<1} \gamma_{i}\right) .
$$

Now assume the theorem true for $k \leqq \gamma_{1}<k+1$, where $k$ is an integer $\geqq 1$. If $S$ satisfies the hypotheses with $k+1 \leqq \gamma_{1}<k+2$, the construction of Theorem 1 can be applied. The only additional detail is that terms like $n^{r}-(n-1)^{r}$ produce infinite series. However, this causes no difficulty, since all but a finite number of terms grow more slowly than $n^{\alpha}$ and can be included in the perturbation term. Thus $S$ is seen to be subcomplete.

Finally, if $S$ is an $R$-sequence, Theorem 2 may be applied to show that $S$ is complete. This completes the proof.

We conclude with a few remarks on possible extensions of the results given. One obvious possibility is to extend the allowable functions $f$ in Theorem 4 . This can certainly be done since it is not hard to see that $f$ may be permitted to be an absolutely convergent infinite series with terms of the form $a_{i} n^{r_{i}}$. More interesting would be an extension to functions satisfying some smoothness condition. Another possibility would be to weaken the condition 
on the perturbation term. A result of [1] shows that Theorem 1 is false with $\alpha>1$. It seems possible that the theorem holds for $\alpha=1$. It would be interesting to weaken the conditions of Theorem 2. Thus, in [2] it is shown that for a sequence of Theorem $A$ to be complete, it suffices that $P(A)$ contain a complete system of residues with respect to every modulus. It seems unlikely that such a weak condition would suffice in the present case, but the author knows no counterexample.

\section{REFERENCES}

1. S. A. Burr and P. Erdös, Completeness properties of perturbed sequences, to appear.

2. J. Folkman, On the representation of integers as sums of distinct terms from a fixed sequence, Canad. J. Math., 18 (1966), 643-655.

3. R. L. Graham, Complete sequences of polynomial values, Duke Math. J., 31 (1964), $275-285$.

4. K. R. Roth and G. Szekeres, Some asymptotic formulae in the theory of partitions, Quarterly J. Math., 5 (1954), 241-259.

Received July 12, 1977 and in revised form May 11, 1979.

The City College

The City University of New York

NEW YORK, NY 10031 


\section{PACIFIC JOURNAL OF MATHEMATICS}

\section{EDITORS}

DONALD BABBITT (Managing Editor)

University of California

Los Angeles, CA 90024

HUgo RossI

University of Utah

Salt Lake City, UT 84112

C. C. Moore and ANDrew OGG

University of California

Berkeley, CA 94720

\section{J. DUGUNDJI}

Department of Mathematics

University of Southern California

Los Angeles, CA 90007

R. FinN and J. MILGRaM

Stanford University

Stanford, CA 94305

\section{ASSOCIATE EDITORS}
E. F. BECKENBACH
B. H. NeumanN
F. WOLF
K. YOSHIDA

\section{SUPPORTING INSTITUTIONS}

UNIVERSITY OF BRITISH COLUMBIA CALIFORNIA INSTITUTE OF TECHNOLOGY

UNIVERSITY OF CALIFORNIA

MONTANA STATE UNIVERSITY

UNIVERSITY OF NEVADA, RENO

NEW MEXICO STATE UNIVERSITY

OREGON STATE UNIVERSITY

UNIVERSITY OF OREGON
UNIVERSITY OF SOUTHERN CALIFORNIA

STANFORD UNIVERSITY

UNIVERSITY OF HAWAII

UNIVERSITY OF TOKYO

UNIVERSITY OF UTAH

WASHINGTON STATE UNIVERSITY

UNIVERSITY OF WASHINGTON

The Supporting Institutions listed above contribute to the cost of publication of this Journal, but they are not owners or publishers and have no responsibility for its content or policies.

Mathematical papers intended for publication in the Pacific Journal of Mathematics should be in typed form or offset-reproduced, (not dittoed), double spaced with large margins. Please do not use built up fractions in the text of the manuscript. However, you may use them in the displayed equations. Underline Greek letters in red, German in green, and script in blue. The first paragraph or two must be capable of being used separately as a synopsis of the entire paper. Please propose a heading for the odd numbered pages of less than 35 characters. Manuscripts, in triplicate, may be sent to any one of the editors. Please classify according to the scheme of Math. Reviews, Index to Vol. 39. Supply name and address of author to whom proofs should be sent. All other communications should be addressed to the managing editor, or Elaine Barth, University of California, Los Angeles, California, 90024.

50 reprints to each author are provided free for each article, only if page charges have been substantially paid. Additional copies may be obtained at cost in multiples of 50 .

The Pacific Journal of Mathematics is issued monthly as of January 1966. Regular subscription rate: $\$ 84.00$ a year (6 Vols., 12 issues). Special rate: $\$ 42.00$ a year to individual members of supporting institutions.

Subscriptions, orders for numbers issued in the last three calendar years, and changes of address should be sent to Pacific Journal of Mathematics, P.O. Box 969, Carmel Valley, CA 93924, U.S.A. Older back numbers obtainable from Kraus Periodicals Co., Route 100, Millwood, NY 10546.

PUBLISHED BY PACIFIC JOURNAL OF MATHEMATICS, A NON-PROFIT CORPORATION

Printed at Kokusai Bunken Insatsusha (International Academic Printing Co., Ltd.). 8-8, 3-chome, Takadanobaba, Shinjuku-ku, Tokyo 160, Japan.

Copyright (C) 1979 by Pacific Journal of Mathematics Manufactured and first issued in Japan 


\section{Pacific Journal of Mathematics}

\section{Vol. 85, No. $2 \quad$ October, 1979}

Charles A. Akemann and Steve Wright, Compact and weakly compact derivations of $C^{*}$-algebras ........................... 253

Dwight Richard Bean, Andrzej Ehrenfeucht and George Frank McNulty, Avoidable patterns in strings of symbols ................... 261

Richard Clark Brown, Notes on generalized boundary value problems in Banach spaces. I. Adjoint and extension theory.................

Kenneth Alexander Brown and John William Lawrence, Injective hulls of group rings .................................... 323

Jacob Burbea, The Schwarzian derivative and the Poincaré metric ....... 345

Stefan Andrus Burr, On the completeness of sequences of perturbed polynomial values ....................................

Peter H. Chang, On the characterizations of the breakdown points of quasilinear wave equations..............................

Joseph Nicholas Fadyn, The projectivity of $\operatorname{Ext}(T, A)$ as a module over

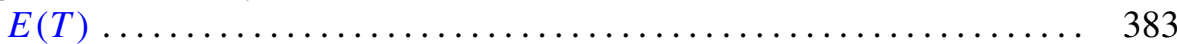

Donald Eugene Maurer, Arithmetic properties of the idèle discriminant .... 393

Stuart Rankin, Clive Reis and Gabriel Thierrin, Right subdirectly irreducible semigroups ................................. 403

David Lee Rector, Homotopy theory of rigid profinite spaces. I ........ 413 Raymond Moos Redheffer and Wolfgang V. Walter, Comparison theorems for parabolic functional inequalities................

H. M. (Hari Mohan) Srivastava, Some generalizations of Carlitz's theorem

James Alan Wood, Unbounded multipliers on commutative Banach algebras....

T. Yoshimoto, Vector-valued ergodic theorems for operators satisfying norm

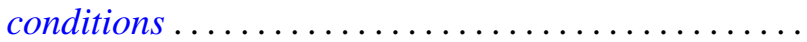

Jerry Searcy and B. Andreas Troesch, Correction to: "A cyclic inequality and a related eigenvalue problem".

Leslie Wilson, Corrections to: "Nonopenness of the set of Thom-Boardman maps" 